\title{
ANÁLISE GEOESTATÍSTICA DA PRECIPITAÇÃO MÉDIA PARA O ESTADO DO PARANÁ
}

\author{
MELLO, Yara Rúbia de - yarademello@gmail.com \\ Universidade Federal do Paraná - UFPR
}

\author{
SAMPAIO, Tony Vinicius Moreira - tony2sampaio@gmail.com \\ Universidade Federal do Paraná - UFPR
}

\begin{abstract}
RESUMO: Técnicas geoestatísticas vêm sendo amplamente utilizadas em análises ambientais, porém, a adequação dos modelos gerados é raramente avaliada, o que gera questionamentos sobre a qualidade dos mesmos. O estado do Paraná como unidade de estudo carece de análises nesta perspectiva, sendo assim, o objetivo deste estudo foi o de realizar um mapeamento geoestatístico detalhado da precipitação média anual, sazonal e mensal para o Paraná, levando em consideração nas análises o alcance espacial das estações pluviométricas. Para tanto, foram utilizados dados pluviométricos das estações disponíveis no site da ANA, com 30 anos de dados e até $10 \%$ de falhas. O mapeamento foi realizado no software ArcGIS, por meio da extensão Geostatistical Analyst. Foi utilizado o método de krigagem ordinária e testados os semivariogramas: esférico, exponencial e gaussiano. Dentre os resultados, observou-se que o modelo de semivariograma que apresentou os melhores ajustes foi o gaussiano, sendo utilizado na geração de $47 \%$ dos mapas. A precipitação média anual para o Paraná é de $1.682,7 \mathrm{~mm}$, sendo o mês de janeiro o mais chuvoso $(194,8 \mathrm{~mm})$, e agosto o mês mais seco $(75,6$ $\mathrm{mm}$ ). As análises demonstraram a importância de se testar diferentes semivariogramas, já que o ajuste dos modelos em relação aos dados pluviométricos não seguiu um padrão. Quanto ao alcance espacial dos pluviômetros, observou-se que de modo geral os meses de verão e os meses de transição com esta estação apresentam os menores alcances espaciais. Já em relação aos ambientes, a região da Serra do Mar apresenta um alcance espacial de suas estações consideravelmente inferior ao do restante do Estado. Concluise com o presente estudo que nos períodos mais chuvosos e principalmente próximos a barreiras orográficas os problemas no processo de interpolação se acentuam. O que torna o mapeamento da precipitação para a região serrana e do litoral do Paraná, nos meses mais chuvosos, relativamente complexo.
\end{abstract}

Palavras-Chave: Alcance espacial, precipitação, semivariograma

\section{GEOSTATISTICAL ANALYSIS OF MEAN PRECIPITATION FOR PARANA STATE}

ABSTRACT: Geostatistical techniques have been widely used in environmental analyzes, however, the adequacy of the models generated is rarely evaluated, which raises questions about their quality. The state of Paraná as a unit of study needs to be analyzed in this perspective. Therefore, the goal of this study was to perform a detailed geostatistical mapping of annual, seasonal and monthly rainfall average for Paraná, taking into account the spatial range of the raingauges. For that, rainfall data were used of the stations available on the ANA website, with 30 years of data and less than $10 \%$ of failures. The mapping was performed in the ArcGIS software, through the Geostatistical Analyst extension. The ordinary kriging method was used and the spherical, exponential and Gaussian semivariograms were tested. Among the results, it was observed that the semivariogram model that presented the best adjustments was the Gaussian one, being used in the generation of $47 \%$ of the maps. The average annual rainfall for Paraná is $1,682.7 \mathrm{~mm}$, with January being the rainiest $(194.8 \mathrm{~mm})$, and August the driest month $(75.6 \mathrm{~mm})$. The analyzes showed the importance of testing different semivariograms, since the adjustment of the models in relation to the rainfall data did not follow a standard. As for the spatial range of the rain gauges, it was observed that in general the summer months and the transition months with this season have the smallest spatial ranges. In relation to the environments, the Serra do Mar region presents a spatial range of its stations considerably lower than the rest of the State. It is concluded with the 
present study that in the rainiest periods and mainly near orographic barriers the problems in the process of interpolation is accentuated. This makes the precipitation mapping for the mountainous and the coastal regions of Paraná, in the rainiest months, relatively complex.

Keywords: Range, precipitation, semivariogram.

\section{ANÁLISIS GEOESTADÍSTICA DE LA PRECIPITACIÓN MEDIA PARA EL ESTADO DEL PARANÁ}

RESUMEN: Las técnicas geoestadísticas vienen siendo ampliamente utilizadas en análisis ambientales, pero la adecuación de los modelos generados es raramente evaluada, lo que genera cuestionamientos sobre la calidad de los mismos. El objetivo de este estudio fue el de realizar un mapeo geoestadístico detallado de la precipitación media anual, estacional y mensual para el Paraná, teniendo en cuenta en los análisis el alcance espacial de las estaciones pluviométricas. Para ello, se utilizaron datos pluviométricos de las estaciones disponibles en el sitio de la ANA, con 30 años de datos y hasta $10 \%$ de fallas. El mapeo se realizó en el software ArcGIS, a través de la extensión Geostatistical Analyst. Se utilizó el método de krigagem ordinario y se probaron los semivariogramas: esférico, exponencial y gaussiano. Entre los resultados, se observó que el modelo de semivariograma que presentó los mejores ajustes fue el gaussiano, siendo utilizado en la generación del $47 \%$ de los mapas. La precipitación media anual para el Paraná es de $1.682,7 \mathrm{~mm}$, siendo el mes de enero el más lluvioso $(194,8 \mathrm{~mm})$, y agosto el mes más seco $(75,6 \mathrm{~mm})$. Los análisis demostraron la importancia de probar diferentes semivariogramas, ya que el ajuste de los modelos en relación a los datos pluviométricos no siguió un patrón. En cuanto al alcance espacial de los pluviómetros, se observó que de modo general los meses de verano y los meses de transición con esta estación presentan los menores alcances espaciales. En cuanto a los ambientes, la región de la Serra do Mar presenta un alcance espacial de sus estaciones considerablemente inferior al del resto del Estado. Se concluye con el presente estudio que en los períodos más lluviosos y principalmente próximos a barreras orográficas los problemas en el proceso de interpolación se acentuan. Lo que hace el mapeo de la precipitación hacia la región serrana y del litoral del Paraná, en los meses más lluviosos, relativamente complejo.

Palabras Clave: Alcance espacial, precipitacíon, semivariograma.

\section{INTRODUÇÃO}

A geoestatística é baseada na teoria das variáveis regionalizadas e tem como objetivo a caracterização espacial de uma variável a partir de um conjunto amostral. Como vantagem, possibilita determinar as incertezas (erros) associadas ao processo de interpolação (YAMAMOTO \& LANDIM, 2013).

A precipitação pluviométrica apresenta dependência espacial e, por ser conhecida a partir das informações coletadas em pontos amostrais, a estimativa de seus valores em locais não amostrados é feita por processos de interpolação. O método geoestatístico possui o diferencial de permitir que seja realizada uma análise da correlação espacial entre as amostras (autocorrelação), permitindo avaliar a pertinência de se estimar valores em locais não amostrados, bem como o erro associado aos valores estimados (MAIR \& FARES, 2011).

É o semivariograma, que juntamente com a covariância fornecem informações relevantes acerca do alcance espacial dos dados, ou seja, indicam a distância mínima necessária entre os locais amostrais (estações de coleta), para que a estimativa em áreas não amostradas seja válida (SAMPAIO \& BRANDALIZE, 2018). O método geoestatístico de krigagem ordinária vem sendo largamente utilizado para caracterizar a precipitação pluviométrica em diferentes contextos climáticos no globo. Diversos estudos, como os de Naoum 
\& Tsanis (2004), Mair \& Fares (2011), Carvalho et al. (2012) e Yavus \& Erdogan (2012) testaram diferentes métodos de interpolação e indicaram especificamente a krigagem ordinária como uma das que apresenta os melhores resultados. Este fato está associado a obtenção dos pesos utilizados na estimativa estatística, o que no caso da krigagem ordinária é feito a partir do emprego da média local.

A quantidade de estudos que utilizam técnicas geoestatísticas para mapear a precipitação aumentou consideravelmente nos últimos anos, contudo a acurácia e conveniência dos mapas e modelos produzidos, nem sempre tem sido foco de análise. Este cuidado se faz necessário, uma vez que a interpolação em áreas de baixa densidade amostral, ainda que por processos geoestatísticos, pode resultar em mapas e modelos com grandes resíduos para os valores estimados, ou até mesmo, em representações inadequadas do fenômeno cartografado.

O estado do Paraná - PR, localizado na Região Sul do Brasil (entre as latitudes $22^{\circ} 30^{\prime} \mathrm{S}$ e $26^{\circ} 43^{\prime} \mathrm{S}$ e longitudes $48^{\circ} 05^{\prime} \mathrm{W}$ e $54^{\circ} 37^{\prime} \mathrm{W}$ Gr.), carece de mapeamentos pluviométricos que apresentem não somente os valores estimados, mas também o erro associado e a pertinência dos mesmos. 0 objetivo deste estudo é realizar um mapeamento geoestatístico da precipitação média anual sazonal e mensal para o Paraná, por meio da técnica de krigagem ordinária, bem como indicar o alcance espacial das estações amostrais na estimação da mesma.

\section{MATERIAIS E MÉTODOS}

Os dados pluviométricos utilizados nesta pesquisa se referem aos disponíveis no site da Agência Nacional de Águas (ANA) para o estado do Paraná, e localidades próximas ao limite do Estado, em Santa Catarina e São Paulo. Foram utilizadas estações com séries históricas iguais ou superiores a 30 anos de observação e com, até no máximo, $10 \%$ de falhas na série. Na etapa de análise prévia foram examinadas a consistência dos valores observados, a presença de outliers (locais e globais) e aplicados testes de homogeneidade e tendência; estas análises estão descritas em Mello \& Sampaio (2017). A série temporal selecionada para a geração dos mapas foi de 1977 a 2006.

A análise geoestatística foi realizada no software ArcGIS por meio da extensão Geostatistical Analyst. Foram gerados mapas do diagrama de Voronoi para cada categoria de análise (anual, verão, outono, etc.) com o intuito de desagregar as amostras e eliminar dados que pudessem enviesar o modelo final. O Modelo Digital de Elevação (MDE) SRTM - Shuttle Radar Topographic Mission, com resolução espacial de 90 metros, foi utilizado para auxiliar nesta análise (http://srtm.csi.cgiar.org/SELECTION/listImages.asp). Com base na observação do relevo, foi a realizada a análise do padrão de distribuição espacial das amostras (estações). Foram realizadas desagregações de amostras (redução de amostras com valores redundantes), somente em casos de recorrência em locais homogêneos do ponto de vista geomorfológico e de condicionantes atmosféricos.

$\mathrm{Na}$ segunda etapa, foram testados os semivariogramas esférico, exponencial e gaussiano, utilizando o método geoestatístico de krigagem ordinária. Segundo Hartkamp et al. (1999) e Li \& Heap (2008) estes modelos de semivariograma são os mais utilizados em análises climatológicas. Alguns dos 
parâmetros avaliados em cada categoria de análise foram: efeito pepita, patamar, alcance, número de passos e tamanho dos passos. O tamanho dos passos foi calculado a partir da distância média entre as estações mais próximas, obtido por meio do uso da ferramenta Average Nearest Neighbor, já o número de passos foi calculado dividindo-se a metade da maior extensão da área de estudo (sentido norte-sul ou leste-oeste) pelo tamanho do passo. Este procedimento é importante para calibrar a variabilidade espacial do fenômeno modelado e evitar a construção desequilibrada do semivariograma no que se refere a quantidade de bipontos.

Ainda nesta etapa, foi calculado o alcance espacial das amostras. Foram utilizados em cada categoria de análise dois períodos classificados como secos, dois como normais e dois como chuvosos, os quais foram definidos por Mello \& Leite (2017). Foram utilizados estes períodos amostrais para avaliar o alcance em diferentes contextos climáticos. Por fim, verificou-se o Índice de Dependência Espacial (IDE), o qual determina faixas de dependência espacial entre a amostra e permite calcular o grau de dependência em função da relação entre o efeito pepita (Co) e o patamar (Co + C) (CAMBARDELLA et al., 1994). O IDE é descrito pela equação:

$$
I D E=\frac{C o}{C o+C} \times 100
$$

\footnotetext{
- $\quad$ IDE $\leq 25 \%$ - forte dependência espacial;

- $\quad$ IDE entre $25 \%$ e $75 \%$ - moderada dependência espacial;

- $\quad$ IDE $\geq 75 \%$ - fraca dependência espacial;

- $\quad$ IDE $=100 \%$ - variável independente espacialmente (efeito pepita puro).
}

Na sequência, as estações foram divididas em amostras de treinamento $(80 \%)$ e validação (20\%). Com as amostras de treinamento foram geradas as superfícies interpoladas de precipitação, que posteriormente foram validadas e calculou-se a raiz quadrada do erro médio (RMS), erro médio (ME) e erro padrão médio (ASE). Com estes resultados foi selecionado o melhor modelo de semivariograma por categoria de análise e gerados os mapas finais.

Para os mapas finais, ainda foram avaliadas as estatísticas da validação cruzada disponibilizadas pelo software utilizado. Com os valores de erros foram gerados (via IDW2) com o intuito de analisar a espacialização das incertezas geradas nas superfícies interpoladas, ou seja, como se distribuem os erros resultantes do processo de interpolação pela área de estudo.

\section{RESULTADOS E DISCUSSÃO}

Com base na avaliação do RMS, ME e ASE, o modelo de semivariograma gaussiano apresentou os melhores resultados para $47 \%$ dos períodos analisados, o modelo esférico em $29 \%$ e o modelo exponencial em $24 \%$ (Tabela 1). Uma observação interessante é que o modelo exponencial apresentou os melhores resultados nos períodos: verão, janeiro, fevereiro e dezembro, ou seja, nos meses mais chuvosos (FRITZSONS et al., 2011) e com a precipitação mais irregular. 
Correa et al. (2014) testaram os modelos esférico, exponencial e gaussiano para mapear a precipitação média anual no estado do Mato Grosso do Sul. Os autores obtiveram os melhores resultados com os modelos esférico e gaussiano. Em contrapartida, Naoum \& Tsanis (2004) utilizaram dados pluviométricos referentes ao dia 8 de maio de 1986 na Suiça e testaram diferentes modelos de interpolação de dados, encontrando melhores resultados com o modelo de krigagem ordinária exponencial. Wanderley et al. (2013) mapearam a precipitação anual para o estado do Alagoas e obtiveram os melhores resultados com os modelos esférico e exponencial. Estes resultados mostram que, mesmo utilizando um método único de estimativa (krigagem ordinária), os modelos que apresentam melhores resultados variam significativamente e não possibilitam estabelecer um modelo prévio para representação da precipitação.

Uliana et al. (2013), mapeando a precipitação mensal e anual provável para o estado do Espírito Santo, obtiveram os melhores resultados com os três modelos: esférico, exponencial, e gaussiano, com destaque para o modelo esférico que obteve os melhores ajustes em $54 \%$ dos períodos analisados. Neste trabalho não foi observado os melhores ajustes do modelo exponencial no período mais chuvoso. Os resultados destas pesquisas juntamente com os do presente estudo mostram como é grande a variabilidade do ajuste dos modelos aos dados, e por isso, a importância de se testar mais de um modelo.

Tabela 1 - Modelo de semivariograma selecionado por categoria de análise e os erros obtidos na validação da amostra de treinamento.

\begin{tabular}{ccccc}
\hline Período & $\begin{array}{c}\text { Modelo } \\
\text { selecionado }\end{array}$ & $\begin{array}{c}\text { Raiz } \\
\text { Quadrada do } \\
\text { Erro Médio } \\
(\mathrm{RMS})\end{array}$ & $\begin{array}{c}\text { Erro } \\
\text { médio } \\
(\mathrm{ME})\end{array}$ & $\begin{array}{c}\text { Erro Padrão } \\
\text { Médio } \\
\text { (ASE) }\end{array}$ \\
\hline Valor ideal & - & $\begin{array}{c}\text { Próximo de } \\
\text { zero }\end{array}$ & $\begin{array}{c}\text { Próximo } \\
\text { de zero }\end{array}$ & $\begin{array}{c}\text { Próximo de } \\
\text { zero }\end{array}$ \\
\hline Anual & Esférico & 93,5 & 20,7 & 99,3 \\
\hline Verão & Exponencial & 35,9 & $-5,6$ & 35,0 \\
Outono & Gaussiano & 29,8 & $-3,7$ & 29,2 \\
Inverno & Esférico & 24,1 & 1,4 & 20,1 \\
Primavera & Gaussiano & 28,7 & 6,2 & 31,9 \\
\hline Janeiro & Exponencial & 18,5 & 0,6 & 15,4 \\
Fevereiro & Exponencial & 15,1 & 0,6 & 17,1 \\
Março & Gaussiano & 10,5 & 0,3 & 13,4 \\
Abril & Gaussiano & 10,4 & 1,5 & 10,4 \\
Maio & Gaussiano & 14,3 & $-0,8$ & 9,6 \\
Junho & Gaussiano & 11,9 & $-0,7$ & 9,2 \\
Julho & Esférico & 10,9 & $-1,8$ & 7,8 \\
Agosto & Esférico & 6,2 & $-0,1$ & 5,7 \\
Setembro & Gaussiano & 9,7 & $-0,4$ & 12,0 \\
Outubro & Gaussiano & 12,4 & $-0,2$ & 12,0 \\
Novembro & Esférico & 11,9 & 1,2 & 11,2 \\
Dezembro & Exponencial & 13,3 & 1,0 & 15,4 \\
\hline
\end{tabular}

Fonte: Elaborada pelos autores (2018). 
O número de estações pluviométricas utilizadas por categoria de análise para a geração dos modelos finais variou de 364 para o período anual a 452 para os meses de junho e julho, essa variação se deve ao número de estações com falhas. Já o tamanho dos passos variou de $12.500 \mathrm{~m}$ (dezembro) a $23.800 \mathrm{~m}$ (novembro), o número de passos mínimo utilizado foi de 20 e o máximo de 24. Os valores destes parâmetros estão disponíveis na Tabela 2.

Tabela 2 - Parâmetros utilizados na análise do semivariograma, alcance espacial e IDE por categoria analisada.

\begin{tabular}{ccccccc}
\hline Período & $\begin{array}{c}\text { Total de } \\
\text { estações }\end{array}$ & $\begin{array}{c}\text { Tamanho } \\
\text { do passo } \\
(\mathrm{m})\end{array}$ & $\begin{array}{c}\text { Número } \\
\text { de } \\
\text { passos }\end{array}$ & $\begin{array}{c}\text { Alcance espacial } \\
\text { (média dos } \\
\text { períodos } \\
\text { amostrais em } \\
\text { km) }\end{array}$ & $\begin{array}{c}\text { Alcance espacial } \\
\text { (menor alcance } \\
\text { amostral em km) }\end{array}$ & $\begin{array}{c}\text { IDE } \\
(\%)\end{array}$ \\
\hline Anual & 364 & 20.000 & 22 & 105 & 87 & 4,5 \\
\hline Verão & 433 & 14.000 & 24 & 66 & 47 & 26,7 \\
Outono & 441 & 20.000 & 24 & 106 & 98 & 11 \\
Inverno & 449 & 18.000 & 24 & 106 & 79 & 0 \\
Primavera & 437 & 18.500 & 24 & 100 & 45 & 7,5 \\
\hline Janeiro & 437 & 14.000 & 20 & 74 & 39 & 24,4 \\
Fevereiro & 437 & 14.000 & 22 & 77 & 45 & 23,5 \\
Março & 443 & 15.000 & 20 & 67 & 87 & 34,5 \\
Abril & 441 & 22.000 & 24 & 85 & 57 & 6,8 \\
Maio & 440 & 16.000 & 24 & 103 & 60 & 5,3 \\
Junho & 452 & 21.000 & 22 & 87 & 83 & 0 \\
Julho & 452 & 20.500 & 22 & 101 & 59 & 0 \\
Agosto & 451 & 20.000 & 24 & 94 & 49 & 14,3 \\
Setembro & 440 & 17.000 & 24 & 92 & 35 & 7,2 \\
Outubro & 440 & 19.000 & 24 & 91 & 35 & 36,4 \\
Novembro & 440 & 23.800 & 24 & 78 & 77 & \\
Dezembro & 440 & 12.500 & 24 & & & 49 \\
\hline
\end{tabular}

Fonte: Elaborada pelos autores (2018).

Ainda na Tabela 2 é possível observar os valores de alcance espacial em relação à média dos períodos amostrais (normais, secos e chuvosos), e o menor alcance encontrado dentro da amostra de cada categoria de análise. Destaca-se que foram considerados $2 / 3$ do valor do alcance como ideal (conforme SAMPAIO \& BRANDALIZE, 2018), para que haja maior confiabilidade na utilização dos dados, sendo estes os valores disponíveis na tabela. Considerando a média dos períodos amostrais, observa-se que, de modo geral, os meses de verão e os meses de transição com esta estação apresentam os menores alcances espaciais, enquanto nos meses de outono, inverno e primavera, principalmente em maio e julho os alcances são maiores. Este resultado condiz com o esperado uma vez que estes períodos apresentam as maiores variabilidades pluviométricas, reduzindo o alcance espacial das estações amostrais.

Utilizando-se como exemplo o mês de novembro, onde na média o alcance é de $78 \mathrm{~km}$ e o menor alcance encontrado na amostra é de $35 \mathrm{~km}$, é possível observar como a variabilidade temporal da precipitação é elevada, lembrando que o alcance espacial é o limite dentro do qual as estações devem 
ser utilizadas no processo de interpolação. Isto mostra que para a interpolação da precipitação média da área de estudo é possível utilizar o alcance médio dos períodos amostrais, porém, para a construção de modelos para períodos específicos (um mês, um dia, etc.) seria recomendável analisar o alcance espacial da amostra para cada caso individual.

O menor alcance espacial não ocorreu necessariamente em um período excepcional (chuvoso ou seco). Os resultados demonstraram que em $35 \%$ dos casos o menor alcance espacial ocorreu em períodos classificados como normal, $35 \%$ em períodos chuvosos e $29 \%$ em períodos secos. O que indica que o padrão de distribuição espacial da precipitação pode ser mais irregular em um período com chuvas dentro do normal (na média do Estado) do que em períodos excepcionais.

Tendo em vista a heterogeneidade da distribuição da precipitação na porção do território paranaense influenciada pela barreira orográfica da Serra do Mar, foram selecionadas estações nas proximidades da mesma para testar o alcance espacial para o período anual nessa região. Foi utilizada a mesma amostra de anos (normais secos, chuvosos e a média de 1977 a 2006), modelo de semivariograma gaussiano, número de passos igual a 7 , e tamanho do passo igual a $16 \mathrm{~km}$. Neste caso, o alcance espacial da amostra diminuiu consideravelmente, sendo a média da amostra testada (alcances) de 30,2 km, o valor máximo de 40,8 km, e o valor mínimo de $11,3 \mathrm{~km}$. Se considerados $2 / 3$ do alcance como distância de segurança para construção de modelos interpolados com baixo resíduos, o alcance espacial ideal para distribuição de estações de monitoramento nesta região seria de aproximadamente $7,5 \mathrm{~km}$.

Quanto ao IDE dos modelos finais, $82 \%$ dos modelos apresentaram forte dependência espacial e $18 \%$ moderada dependência espacial. Os períodos com os valores de IDE mais elevados (menor dependência espacial) são justamente os meses de verão (dezembro, janeiro e fevereiro), março e a estação verão. Períodos nos quais a distribuição de precipitação é mais irregular, devido principalmente ao tipo de precipitação que ocorre, a convectiva, que apresenta uma característica de distribuição espacial mais variável. Esse padrão pode ser observado nas Figuras 1 e 2, as quais trazem os semivariogramas dos modelos finais de precipitação, onde é possível observar os valores de efeito pepita (irregularidades a curtos espaçamentos) mais elevados para o período citado. 


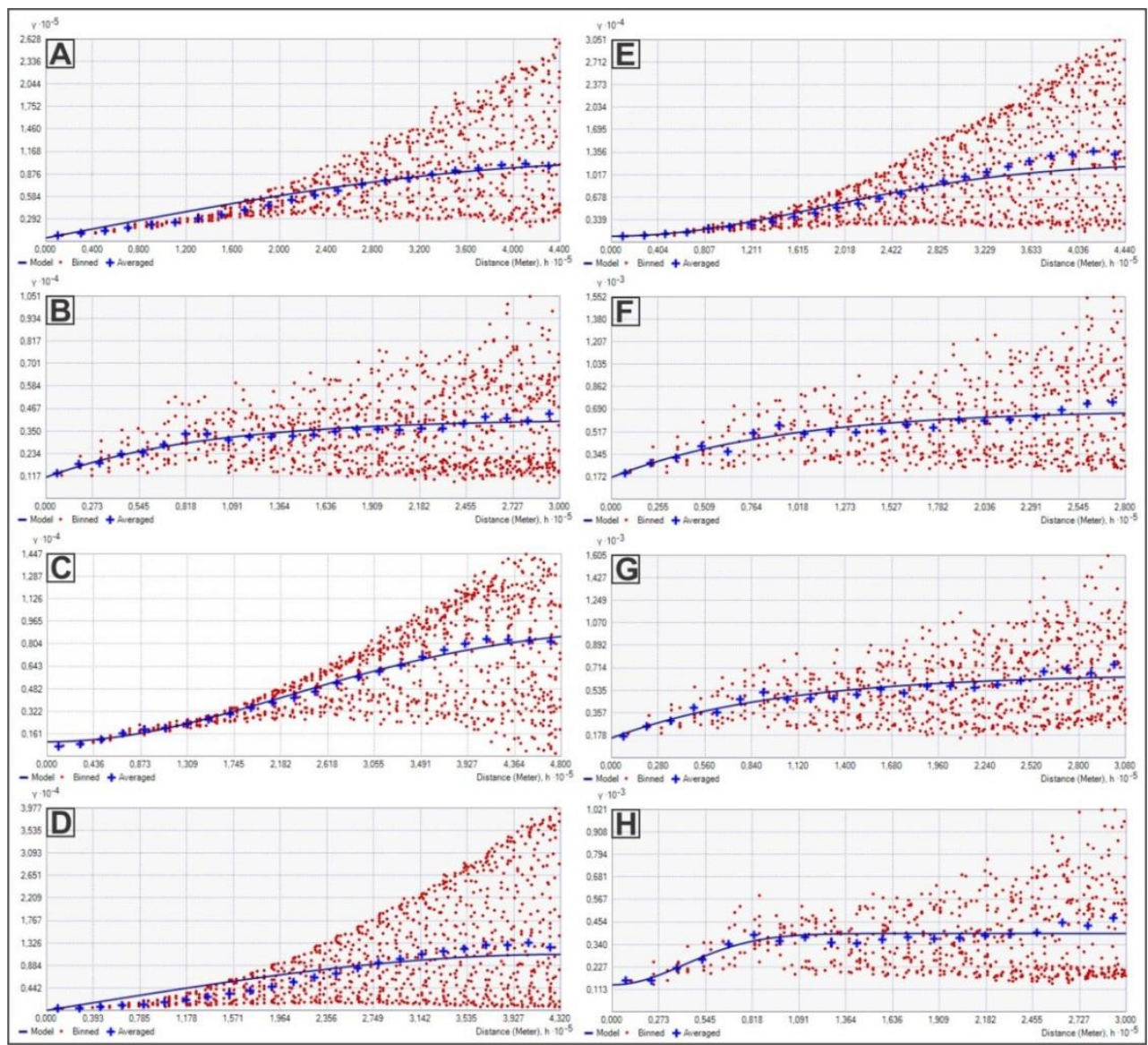

Figura 1 - Semivariogramas referente aos modelos de precipitação (1977-2006) selecionados para o estado do Paraná. Legenda: A) anual; B) verão; C) outono; D) inverno; E) primavera; F) janeiro; G) fevereiro; e H) março. Fonte: Elaborada pelos autores (2018). 


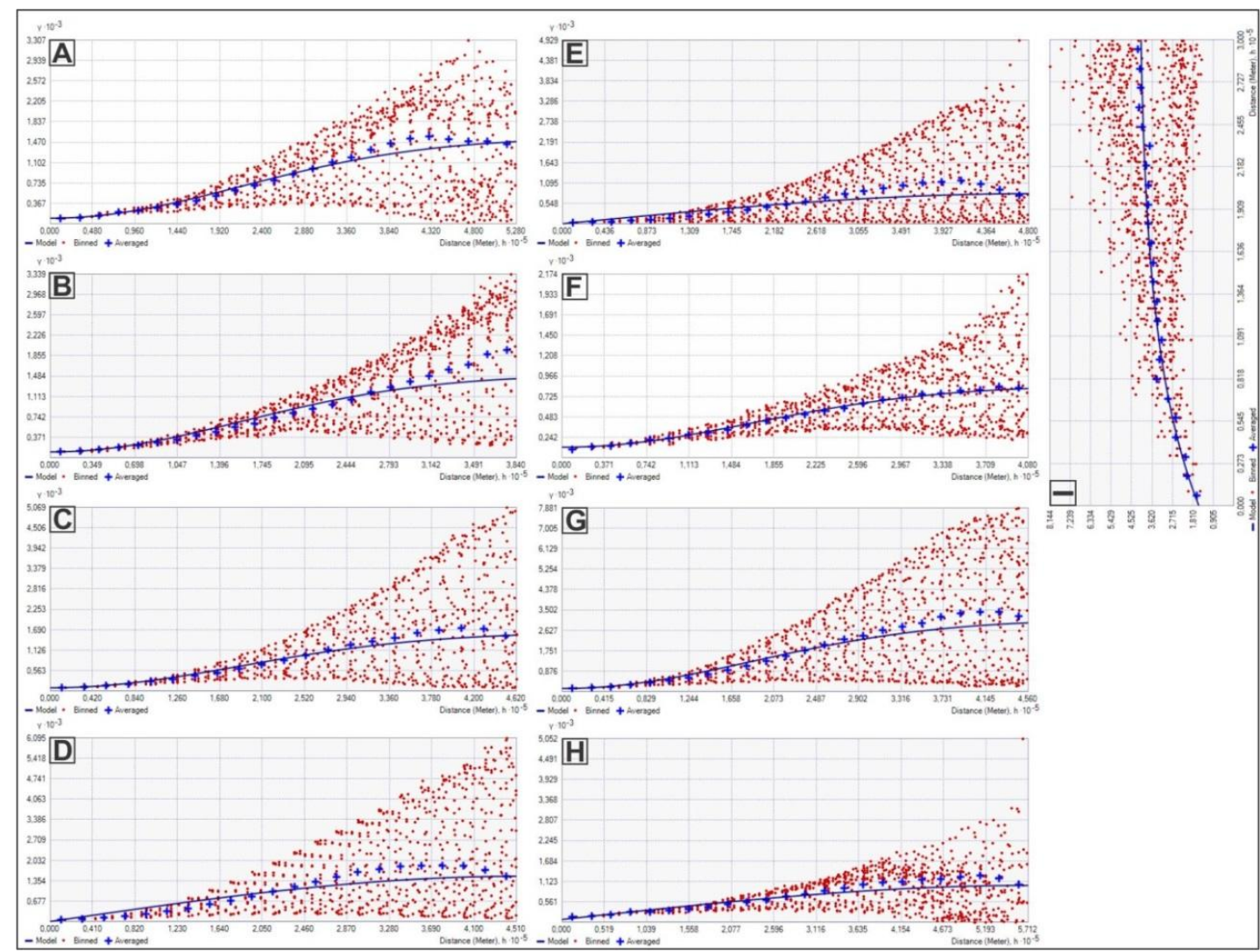

Figura 2 - Semivariogramas referente aos modelos de precipitação (1977-2006) selecionados para o estado do Paraná. Legenda: A) abril; b) maio; C) junho; D) julho; E) agosto;F) setembro; G) outubro; H) novembro; e I) dezembro. Fonte: Elaborada pelos autores (2018).

Na Tabela 3 estão descritas as estatísticas de erros da validação cruzada para os modelos de precipitação selecionados para cada categoria de análise. De modo geral, todos os modelos apresentaram valores que podem ser considerados baixos. Destaca-se que novamente os maiores erros foram encontrados no período do verão.

Tabela 3 - Estatísticas dos erros da validação cruzada obtidas nos modelos interpolados selecionados por categoria analisada.

\begin{tabular}{ccccc} 
Erros & $\begin{array}{c}\text { Média } \\
\text { Padronizada } \\
(\text { MS) }\end{array}$ & $\begin{array}{c}\text { Raiz } \\
\text { Quadrada do } \\
\text { Erro Médio } \\
\text { Padronizado } \\
\text { (RMSS) }\end{array}$ & $\begin{array}{c}\text { Erro Padrão } \\
\text { Médio (ASE) }\end{array}$ & $\begin{array}{c}\text { Raiz Quadrada do } \\
\text { Erro Médio (RMS) }\end{array}$ \\
\hline Valor & $\begin{array}{c}\text { Próximo de } \\
\text { zero }\end{array}$ & $\begin{array}{c}\text { Próximo de } \\
\text { um }\end{array}$ & Próximo do RMS & Menor possível \\
\hline ideal & $-0,003$ & 1,025 & 102,544 & 108,824 \\
\hline Anual & $-0,003$ & 1,021 & 42,609 & 44,105 \\
Verão & 0,000 & 0,952 & 33,061 & 31,680 \\
Outono & 0,000 & 1,033 & 24,224 & 23,799 \\
Inverno & 0 & &
\end{tabular}




\begin{tabular}{ccccc} 
Primavera & $-0,010$ & 1,062 & 31,134 & 33,210 \\
\hline Janeiro & $-0,001$ & 1,006 & 16,918 & 17,159 \\
Fevereiro & $-0,004$ & 1,016 & 16,212 & 16,772 \\
Março & $-0,003$ & 1,004 & 12,986 & 13,217 \\
Abril & 0,002 & 1,021 & 10,352 & 10,624 \\
Maio & $-0,018$ & 1,084 & 10,624 & 11,527 \\
Junho & 0,003 & 1,080 & 9,438 & 10,224 \\
Julho & $-0,002$ & 1,156 & 8,733 & 9,644 \\
Agosto & $-0,002$ & 1,159 & 6,209 & 6,856 \\
Setembro & $-0,018$ & 1,007 & 11,473 & 11,600 \\
Outubro & $-0,010$ & 1,128 & 11,905 & 13,503 \\
Novembro & 0,000 & 1,082 & 11,329 & 12,174 \\
Dezembro & $-0,002$ & 0,998 & 14,843 & 14,857 \\
\hline
\end{tabular}

Fonte: Elaborada pelos autores (2018).

A partir do mapa final foi possível inferir que a precipitação média anual para o estado do Paraná é de $1.682,7 \mathrm{~mm}$, sendo que os valores máximos são encontrados na região a barlavento da Serra do Mar, próximo ao Oceano Atlântico, e os valores mínimos na porção norte do Estado (Figuras 3 e 4A). Com base no modelo esférico selecionado, os municípios mais chuvosos são respectivamente Guaraqueçaba $(2.234,5 \mathrm{~mm})$, Pontal do Paraná $(2.189,5 \mathrm{~mm})$, Paranaguá $(2.180,2 \mathrm{~mm})$, Matinhos $(2.131,3 \mathrm{~mm})$ e Flor da Serra do Sul $(2.074,9 \mathrm{~mm})$, todos localizados na planície costeira e serra, na porção leste do Estado, exceto Flor da Serra do Sul, que está localizado na porção sudoeste.

Em contrapartida, os municípios com os menores acumulados de precipitação são Diamante do Norte $(1.305,7 \mathrm{~mm})$, Itaúna do Sul $(1.334,1 \mathrm{~mm})$, São Pedro do Paraná $(1.335,6 \mathrm{~mm})$, Leópolis $(1.336,6 \mathrm{~mm})$ e Porto Rico $(1.337,5 \mathrm{~mm})$. Localizados na porção noroeste e centro-norte do Estado.

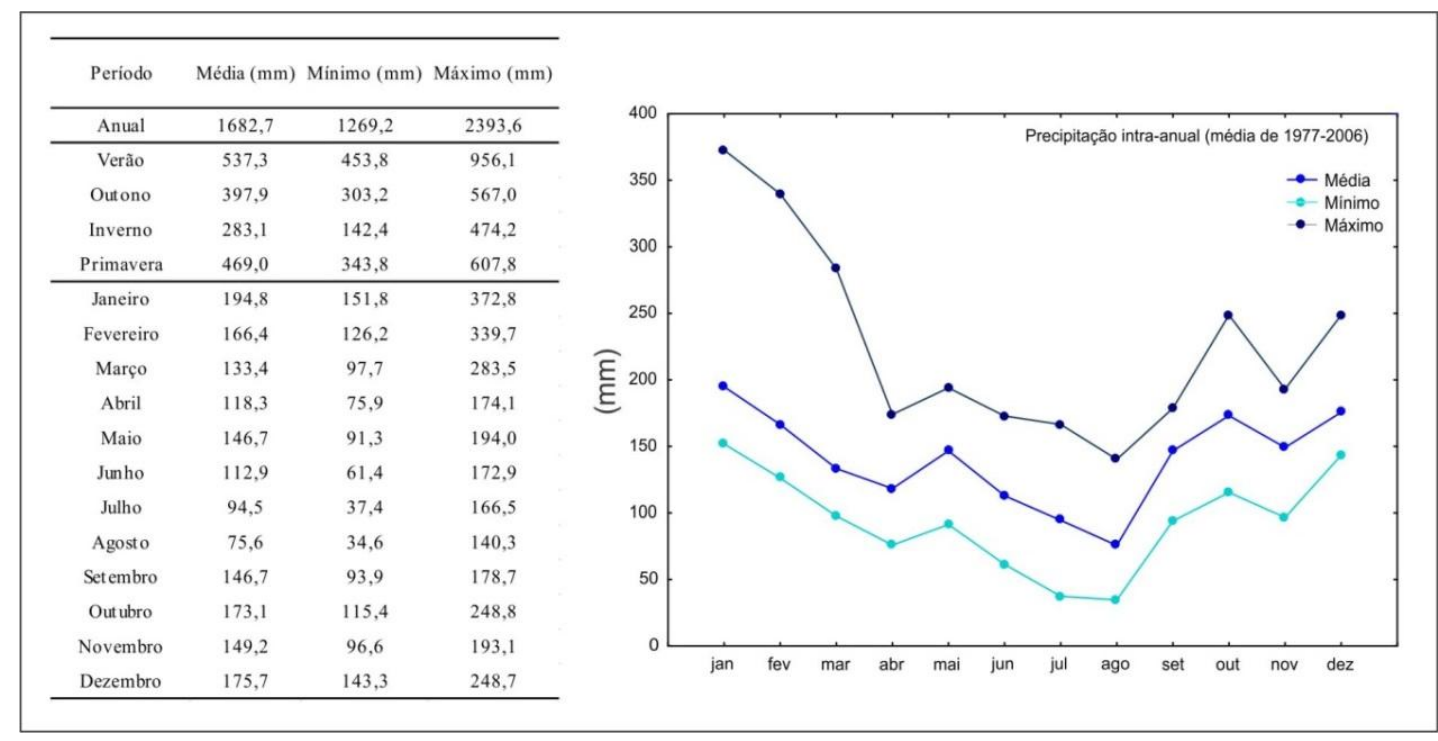

Figura 3 - Valores médios, mínimos e máximos de precipitação referente aos modelos de precipitação (1977-2006) selecionados para o estado do Paraná. Fonte: Elaborada pelos autores (2018). 
Na Figura 4 estão representados os mapas de precipitação anual para o modelo esférico (selecionado), gaussiano e exponencial, além do mapa de diagrama de Voronoi com os valores médios de precipitação anual. Os modelos esférico e gaussiano apresentaram resultados similares na etapa de validação, porém, optou-se pelo modelo esférico porque ele apresentou resultados mais próximos, menos suavizados, permitindo visualizar melhor a variabilidade espacial do modelo. Como pode ser observado, por exemplo, nos círculos vermelhos destacadas na Figura 4, os quais indicam uma região com precipitação elevada em relação ao entorno, a leste da Escarpa Devoniana, destacada nos modelos esférico e exponencial. Já o modelo gaussiano representou essa região como uma contínua área de sombra de chuva, o que não condiz com a realidade.

Tang (2002) encontrou resultados distintos do presente estudo, o autor testou diferentes modelos de semivariograma para o período mensal (19611998) a partir dos dados de 61 estações pluviométricas localizadas no leste da China. O autor observou que os modelos esférico e exponencial resultaram em superfícies interpoladas mais suavizadas, enquanto o modelo gaussiano foi um modelo mais exato.

O verão é a estação do ano mais chuvosa $(537,3 \mathrm{~mm})$, enquanto o inverno é a estação do ano menos chuvosa $(283,1 \mathrm{~mm})$, com uma amplitude de $254 \mathrm{~mm}$ (Figuras 3 e 5). Resultado semelhante foi encontrado por Fritzsons et al. (2011) para o mesmo período de dados (1977-2006), analisando 469 estações, os autores observaram uma média de $533,9 \mathrm{~mm}$ para o verão e de $290 \mathrm{~mm}$ para o inverno, neste trabalho não foram gerados mapas. No verão e outono a precipitação é maior na porção leste do Estado, a barlavento da Serra do Mar; no inverno a precipitação é maior na porção sudoeste; e na primavera em ambas as regiões citadas com destaque para a última. Wrege et al. (2012), no Atlas Climático da Região Sul do Brasil, encontraram resultados semelhantes, porém, com algumas diferenciações no verão, que além da precipitação ser maior na área leste do Estado, também há um destaque para a região central, entre Cascavel e Londrina. 


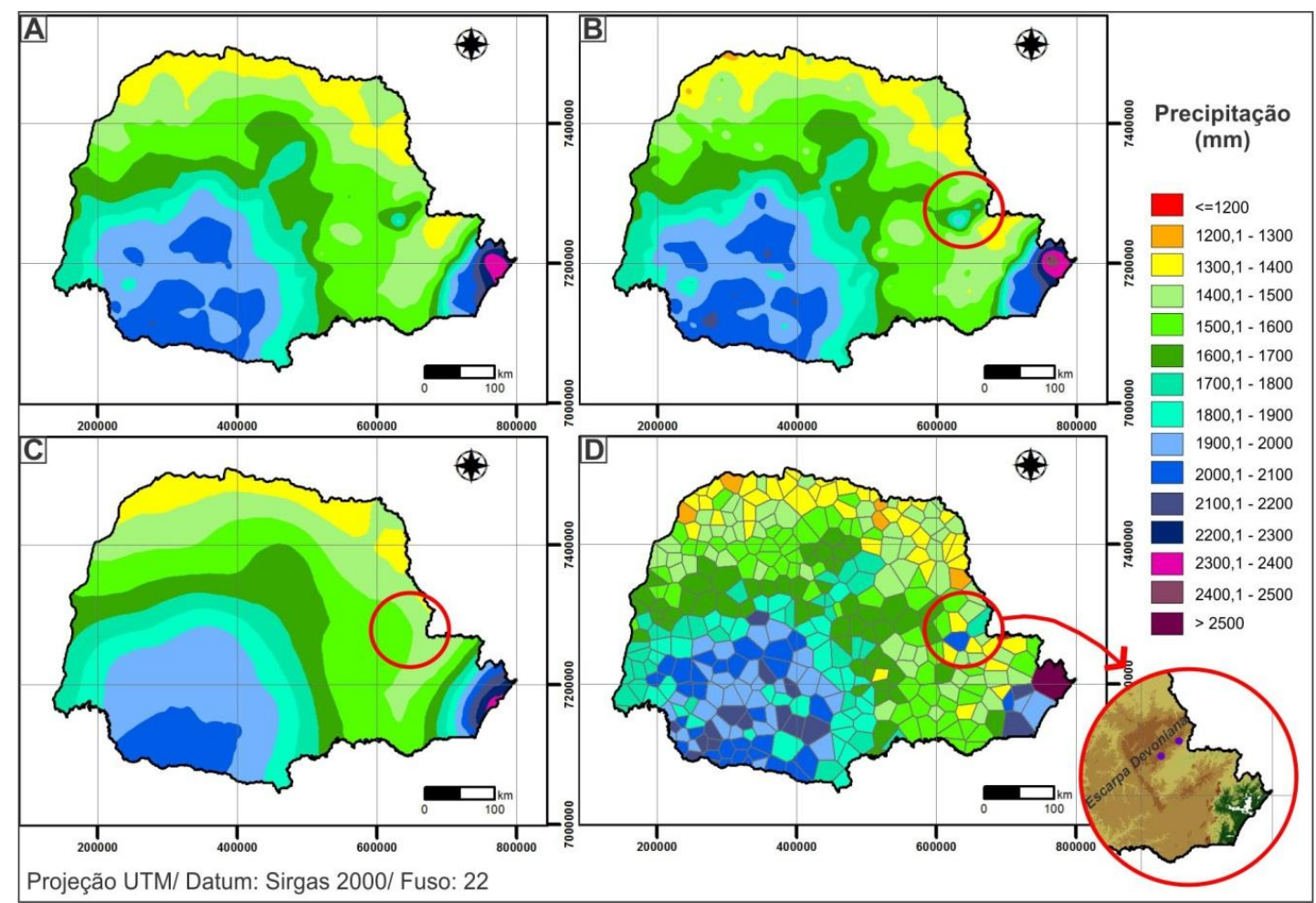

Figura 4 - Precipitação média anual (1977-2006) para o estado do Paraná. Legenda: A) modelo esférico (selecionado); B) modelo exponencial; C) modelo gaussiano; e D) mapa de diagrama de Voronoi com destaque para duas estações localizadas a leste da Escarpa Devoniana. Fonte: Elaborada pelos autores (2018).

Ainda na Figura 5 é possível observar como o inverno é a estação do ano mais crítica em relação aos baixos acumulados de precipitação, principalmente na porção norte do Estado, com acumulados inferiores a $150 \mathrm{~mm}$. Apesar de no inverno chover mais na porção sudoeste do Estado, esta não é a estação do ano que chove mais nesta região, as estações de primavera e verão são as mais chuvosas. 


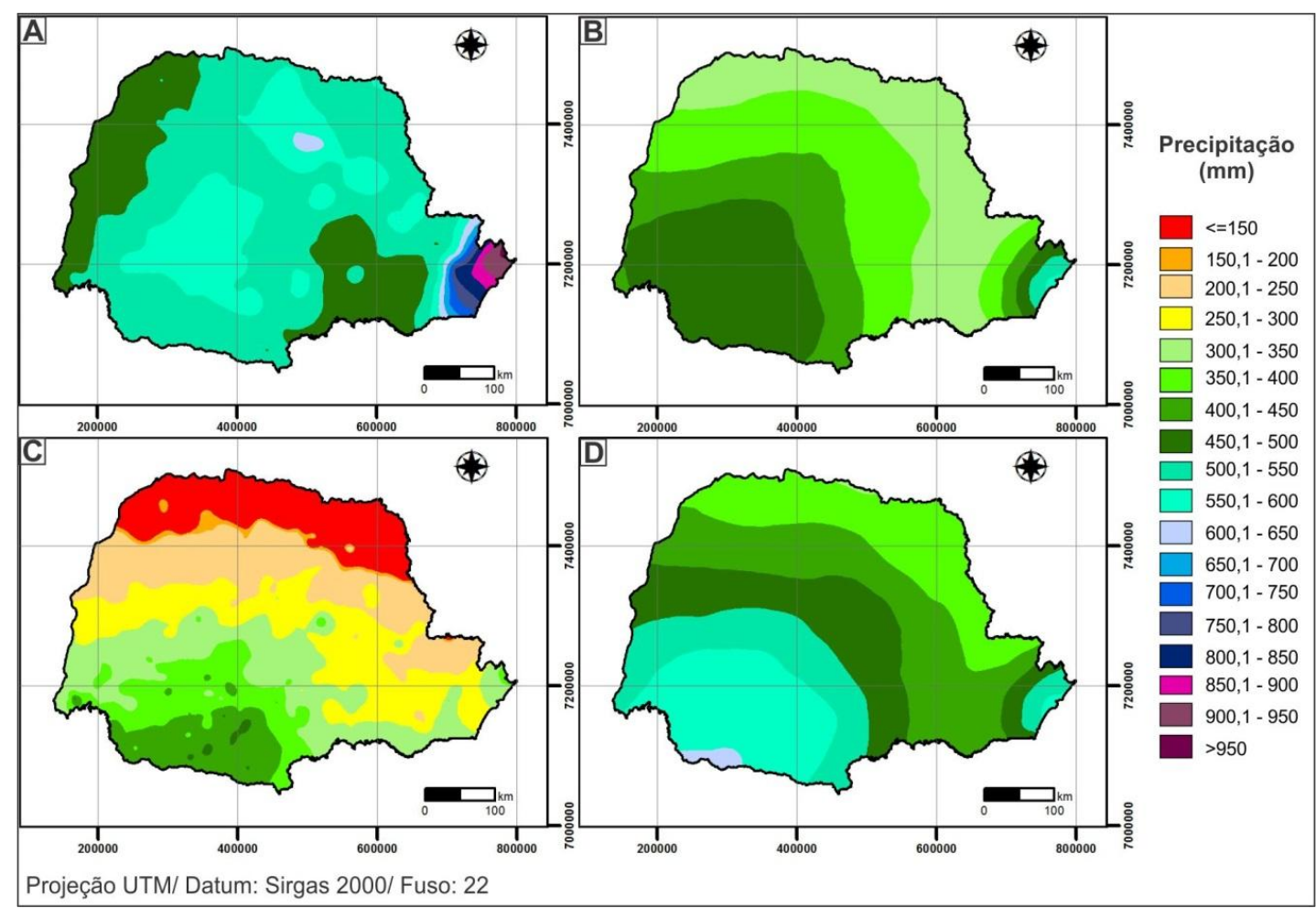

Figura 5 - Precipitação média sazonal (1977-2006) para o estado do Paraná. Legenda: A) verão; B) outono; C) inverno; e D) primavera. Fonte: Elaborada pelos autores (2018).

Quanto à distribuição intra-anual da precipitação média no estado do Paraná, o mês de janeiro é o mês mais chuvoso $(194,8 \mathrm{~mm})$ e o mês de agosto é o mês mais seco $(75,6 \mathrm{~mm}$ ), com uma amplitude de $119 \mathrm{~mm}$ (Figuras 3, 6, 7 e 8). Nos meses de janeiro, fevereiro e março a precipitação é destacadamente maior nas áreas de planície costeira, a barlavento da Serra do Mar. Por outro lado, nos meses de maio, junho, julho e agosto as precipitações são mais elevadas na porção sudoeste do Estado. De setembro a dezembro os acumulados pluviométricos nestas duas regiões são mais semelhantes, porém, em outubro ainda chove mais no sudoeste do Estado e em dezembro as chuvas aumentam no litoral - se aproximando da dinâmica de janeiro a março na região. 

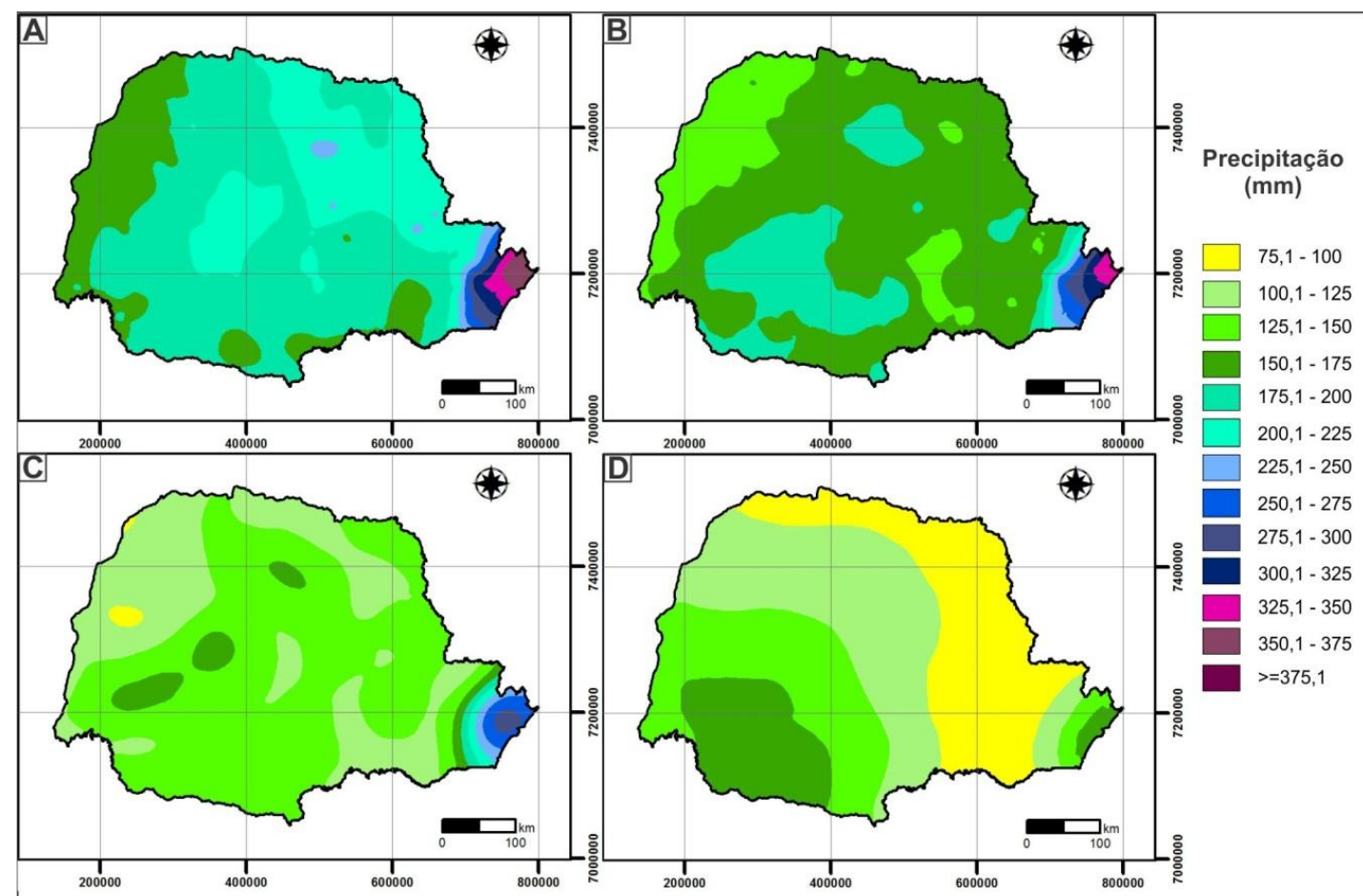

Projeção UTM/ Datum: Sirgas 2000/ Fuso: 22

Figura 6 - Precipitação média mensal (1977-2006) para o estado do Paraná. Legenda: A) janeiro; B) fevereiro; C) março; e D) abril. Fonte: Elaborada pelos autores (2018).

Para a porção oeste do Estado, principalmente nos meses de janeiro, fevereiro e março, existe um padrão de menor precipitação no sentido oesteleste - com os maiores acumulados nesta última direção. De abril a novembro o padrão de precipitação nesta região se dá com os maiores acumulados na porção sul, diminuindo para o norte. Nos meses de julho e agosto a distribuição de precipitação segue um padrão latitudinal, com os maiores acumulados na porção sul e os menores na porção norte - essa dinâmica se estende para todo o Estado. 


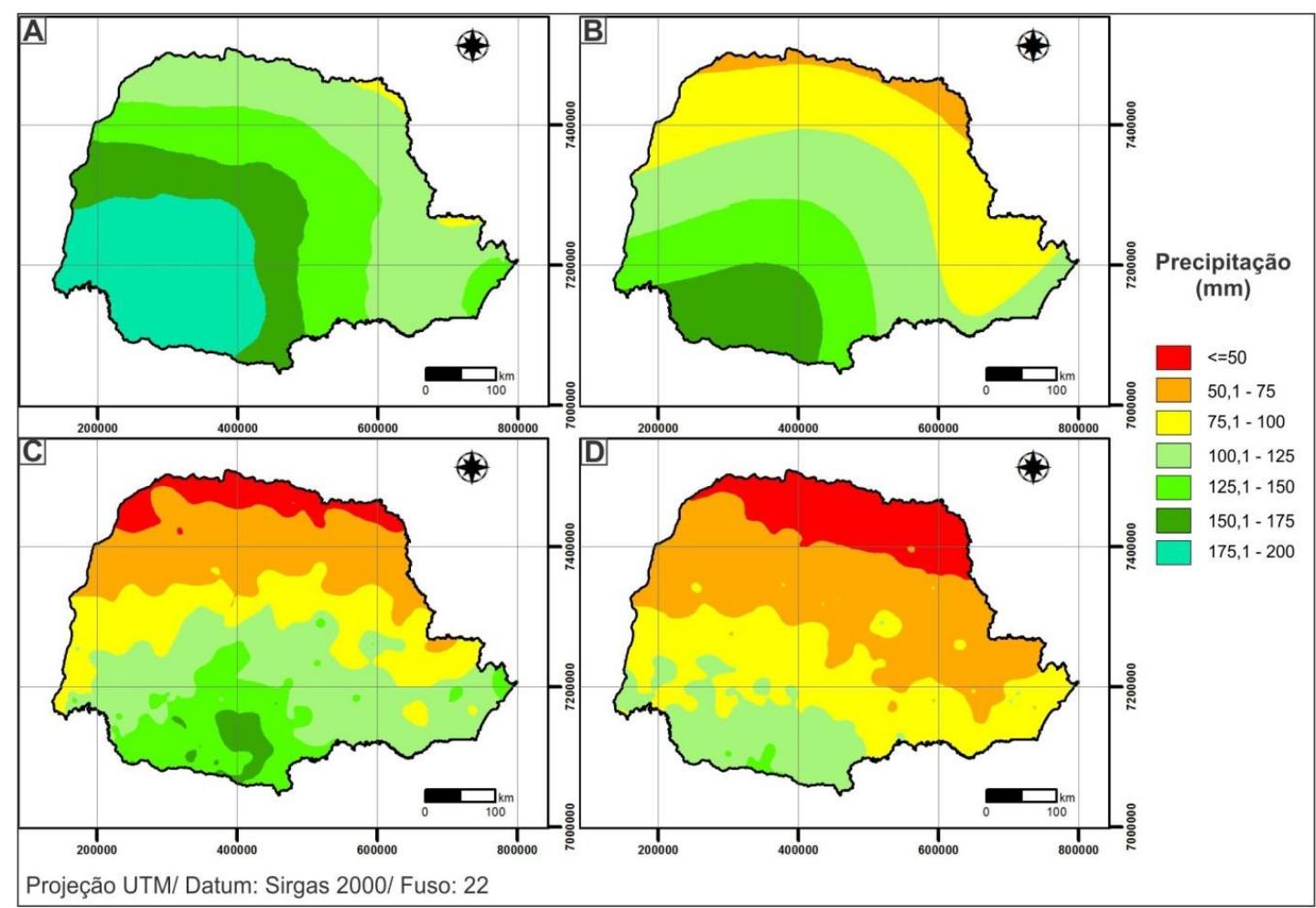

Figura 7 - Precipitação média mensal (1977-2006) para o estado do Paraná. Legenda: A) maio; B) junho; C) julho; e D) agosto. Fonte: Elaborada pelos autores (2018).

Quanto à espacialização dos erros no processo de interpolação, a maior concentração de erros subestimados se deu na estação Guaraqueçaba localizada nas proximidades da frente da Serra do Mar, na estação Ilha do Rio Claro (São José dos Pinhais) - localizada na Serra do Mar, e em parte da planície costeira. Enquanto os erros superestimados se concentraram na estação Barra do Rio Turvo - localizada no vale do rio Ribeira do Iguapé, na região de planalto adjacente a Serra do Mar e em parte da planície costeira. Ou seja, a maior concentração de erros se deu na região da Serra do Mar e adjacências. Porém, para os meses de junho, julho e agosto (inverno) essa região obteve um mapeamento mais acurado, com erros inferiores a $10 \mathrm{~mm}$. 


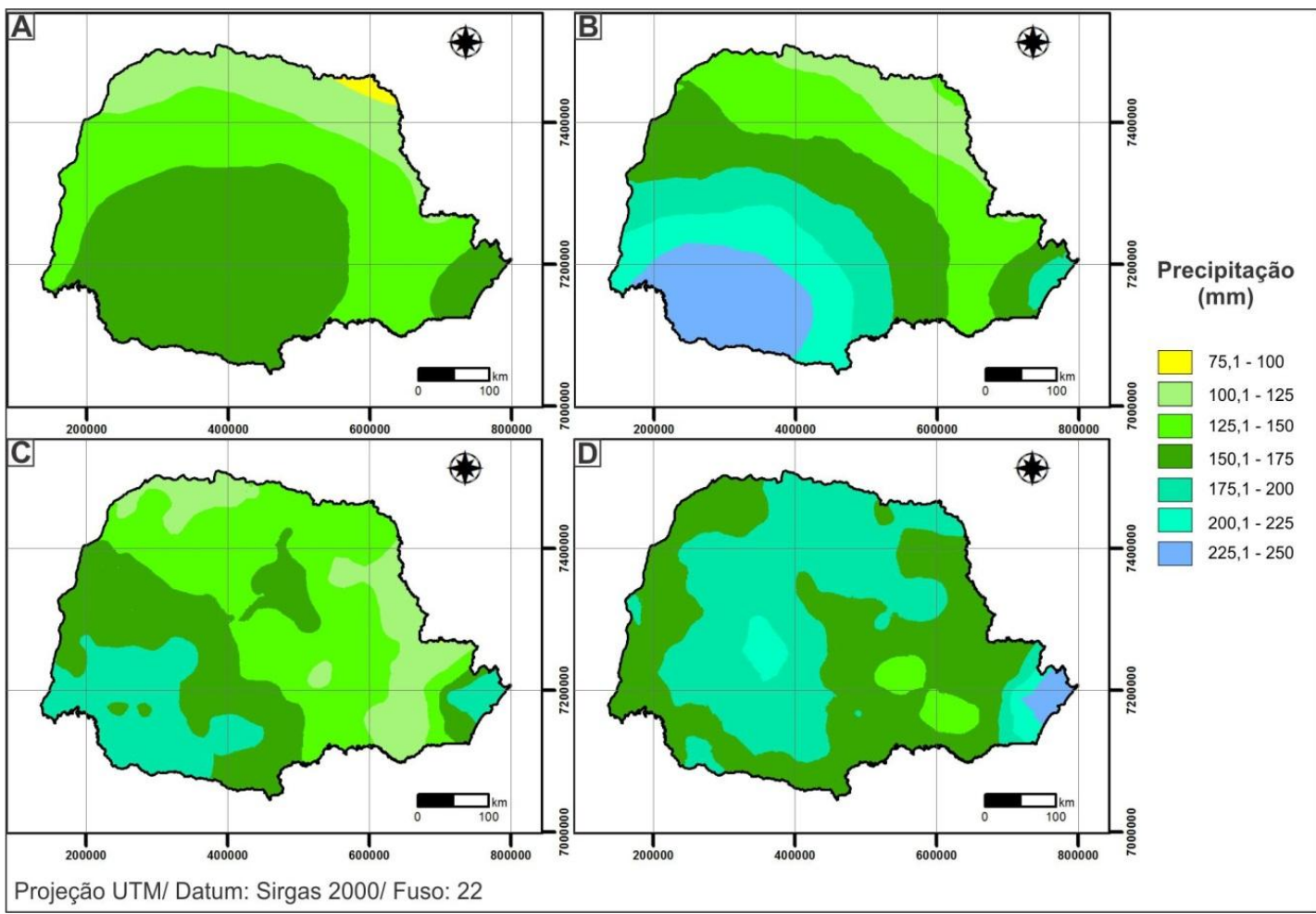

Figura 8 - Precipitação média mensal (1977-2006) para o estado do Paraná. Legenda: A) setembro; B) outubro; C) novembro; e D) dezembro. Fonte: Elaborada pelos autores (2018).

Em relação à série temporal, os maiores erros se deram nos meses mais chuvosos (janeiro, fevereiro, março e dezembro). No mês de abril a concentração de erros acima de $10 \mathrm{~mm}$ se deu na porção sudoeste do Estado. Os meses de junho, julho, agosto e novembro apresentaram poucos erros acima de $10 \mathrm{~mm}$ para todo o Paraná.

Para o período anual a amplitude dos erros foi de -700 a $335 \mathrm{~mm}$, para o verão foi de -290 a $167 \mathrm{~mm}$, no inverno foi de -124 a $70 \mathrm{~mm}$, no mês de janeiro foi de -104 a $66 \mathrm{~mm}$ e no mês de agosto foi de -38 a $22 \mathrm{~mm}$. Estes valores extremos de erros são muito pontuais, a maior parcela dos erros para o período anual foi inferior a $50 \mathrm{~mm}$ (84\%). No verão $86 \%$ e no inverno $97 \%$ dos erros foram inferiores a $25 \mathrm{~mm}$; por fim, em janeiro $87 \%$ e em agosto $99 \%$ dos erros foram inferiores a $10 \mathrm{~mm}$.

\section{CONSIDERAÇÕES FINAIS}

O semivariograma é uma ferramenta que pode auxiliar no diagnóstico de períodos excepcionais (chuvosos e secos) e normais. Todos os modelos de semivariograma testados (esférico, exponencial e gaussiano) foram utilizados no mapeamento, demonstrando a importância de se testar diferentes semivariogramas, já que o ajuste dos modelos em relação aos dados não seguiu um padrão. Destaca-se que o modelo exponencial apresentou os melhores ajustes para os períodos mais chuvosos do ano e o modelo gaussiano foi utilizado na geração de $47 \%$ dos mapas. 
Acredita-se que nos períodos mais chuvosos e principalmente próximos a barreiras orográficas os problemas no processo de interpolação se acentuem. 0 que torna o mapeamento da precipitação para a região serrana e do litoral do Paraná, nos meses mais chuvosos, relativamente complexo. A baixa densidade de estações nessa porção do território dificulta ainda mais as análises. Ao mesmo tempo estas incertezas abrem espaço para novas pesquisas que procurem preencher esta lacuna na produção científica. Por fim, esta pesquisa fornece subsídios para definir grids amostrais para a modelagem da precipitação no estado do Paraná.

\section{REFERÊNCIAS}

CAMBARDELLA, C. A.; MOORMAN, T. B.; NOVAK, J. M.; PARKIN, T. B.; KARLEM, D. L.; TURCO, R. F.; KONOPA, A. E. Field scale variability of soil properties in central Iowa soil. Soil Science Society of America Journal, v.58, p.1501-1511, 1994.

CARVALHO, J. R. P. de; ASSAD, E. D.; PINTO, H. S. Interpoladores geoestatísticos na análise da distribuição espacial da precipitação anual e de sua relação com altitude. Pesquisa Agropecuária Brasileira, v.47, n.9, p.1235-1242, 2012.

CORREA, C. C. G.; TEODORO, P. E.; CUNHA, E. R. da; OLIVEIRA-JÚNIOR, J. F. de; GOIS, G.; RIBEIRO, L. P.; BACANI, V. M.; TORRES, F. E. Spatial Interpolation of Annual Rainfall in the State Mato Grosso Do Sul (Brazil) Using Different Transitive Theoretical Mathematical Models. International Journal of Innovative Research in Science, Engineering and Technology, v.3, n.10, p.16618-16625, 2014.

FRITZSONS, E.; MANTOVANI, L. E.; WREGE, M. S.; NETO, A. C. Análise da pluviometria para definição de zonas homogêneas no Estado do Paraná. RA'E GA, v. 23, p. 555-572, 2011.

HARTKAMP, A. D.; DE BEURS, K.; STEINS, A.; WHITE, J. W. 1999. Interpolation techniques for climate variables. NRG-GIS Series 99-01. Mexico, D. F.: CIMMYT.

LI, J; HEAP, A. D. A review of spatial interpolation Methods for Environmental Scientists. Geoscience Australia Record. 2008.

MAIR, A.; FARES, A. Comparison of Rainfall Interpolation Methods in a Mountainous Region of a Tropical Island. J. Hydrol. Eng., 16(4):371-383, 2011.

MELLO, Y. R.; LEITE, M. B. Caracterização da precipitação mensal, sazonal e anual para o estado do Paraná em períodos secos, normais e chuvosos. In: Archimedes Perez Filho; Raul Reis Amorim (Org.). Os desafios da Geografia Física na Fronteira do Conhecimento. 1ed. Campinas: Instituto de Geociências, UNICAMP, 2017, p.2127-2137.

MELLO, Y. R.; SAMPAIO, T. V. M. Análise estatística preliminar de dados pluviométricos mensais, sazonais e anuais para o Estado do Paraná. In: Archimedes Perez Filho; Raul Reis Amorim (Org.). Os desafios da Geografia Física na Fronteira do Conhecimento. 1ed. Campinas: Instituto de Geociências, UNICAMP, 2017, p.1532-1543.

NAOUM, S.; TSANIS, I. K. Ranking spatial interpolation techniques Using a GISbased DSS. Global Nest: the Int. J., v.6, n.1, p.1-20, 2004. 
SAMPAIO, T. V. M.; BRANDALIZE, M. C. B. Geotecnologias: Teoria e Prática. Curitiba: Programa de Pós-Graduação em Ciências Geodésicas da UFPR, 2018.

TANG, Y. Comparison of semivariogram models for kriging monthly rainfall in eastern China. Journal of Zhejiang University SCIENCE, v.3, n.5, p.584-590, 2002.

ULIANA, T. M., REIS, E. F., SILVA, J. G. F. and XAVIER, A. C. "Precipitação mensal e anual provável para o Estado do Espírito Santo", Irriga, v.18, n.1, pp.139-147, 2013.

WANDERLEY, H. S., AMORIM, R. F. C. and CARVALHO, F. O. "Interpolação espacial da precipitação no Estado de Alagoas utilizando técnicas geoestatística", Revista Ciências Exatas e da Terra e Ciências Agrárias, v.8, n.1, pp.34-42, 2013.

WREGE, M. S.; STEINMETZ, S.; REISSER JÚNIOR, C.; ALMEIDA, I. R. de. Atlas Climático da Região Sul do Brasil. Brasília: Embrapa, 2012.

YAMAMOTO, J.K.; LANDIM, P. M. B. Geoestatística: conceitos e aplicações. São Paulo: Oficina de Textos, 2013.

YAVUS, H.; ERDOGAN, S. Spatial Analysis of Monthly and Annual Precipitation Trends in Turkey. Water Resour Manage, 26:609-621, 2012. 